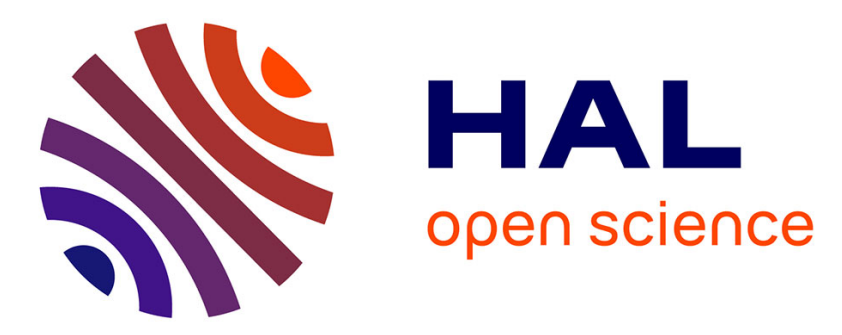

\title{
Acoustic variability and social significance of calls in female Campbell's monkeys (Cercopithecus campbelli campbelli)
}

\author{
Alban Lemasson, Martine Hausberger
}

\section{- To cite this version:}

Alban Lemasson, Martine Hausberger. Acoustic variability and social significance of calls in female Campbell's monkeys (Cercopithecus campbelli campbelli). Journal of the Acoustical Society of America, 2011, 129 (5), pp.3341-3352. 10.1121/1.3569704 . hal-01022082

\section{HAL Id: hal-01022082 \\ https://hal.science/hal-01022082}

Submitted on 5 Sep 2019

HAL is a multi-disciplinary open access archive for the deposit and dissemination of scientific research documents, whether they are published or not. The documents may come from teaching and research institutions in France or abroad, or from public or private research centers.
L'archive ouverte pluridisciplinaire $\mathbf{H A L}$, est destinée au dépôt et à la diffusion de documents scientifiques de niveau recherche, publiés ou non, émanant des établissements d'enseignement et de recherche français ou étrangers, des laboratoires publics ou privés. 


\title{
Acoustic variability and social significance of calls in female Campbell's monkeys (Cercopithecus campbelli campbelli)
}

\author{
A. Lemasson ${ }^{\text {a) }}$ and M. Hausberger \\ Université de Rennes 1, Unité Mixte de Recherche 6552 Centre de Recherche Scientifique, EthoS - Ethologie \\ animale et humaine, Station Biologique 35380 Paimpont, France
}

(Received 25 June 2009; revised 16 December 2009; accepted 23 February 2011)

\begin{abstract}
Although the vocal repertoire of nonhuman primates is strongly constrained by genetic, a growing number of studies evidence socially determined flexibility. According to Snowdon et al. [Social Influences on Vocal Development (University Press, Cambridge, 1997), pp. 234-248], calls with a higher social function (affiliative or agonistic) would be expected to show more flexibility than lesser social calls. Owren and Rendall [Evol. Anthropol., 10, 58-71 (2001)] nuanced this by defending a structure-function relationship. Calls with particular acoustic properties, which directly influence the listener's affect, would be less individually distinctive than calls involved in an affective conditioning process. These hypotheses were tested in Campbell's monkeys using telemetric recordings. This is the first detailed description of female Campbell's monkeys' vocal repertoire emphasizing a possible relationship between social function and flexibility level. The vocal repertoire displayed an "arborescent" organization (call type, subtype, and variants). The highest number of subtypes and the greatest acoustic variability, within and among individuals, were found in calls associated with the highest affiliative social value. However, calls associated with agonism were the most stereotyped, whereas less social alarm calls were intermediate. This only partially validate the hypothesis of Snowdon et al. In accordance with Owren and Rendall's hypotheses, the level of individual distinctiveness was minimum for noisy pulsed calls and maximum for calls involved in affiliative interactions. (C) 2011 Acoustical Society of America. [DOI: 10.1121/1.3569704]
\end{abstract}

PACS number(s): 43.80.Ka [ADP]

Pages: 3341-3352

\section{INTRODUCTION}

Whether or not the acoustic variability observed in nonhuman primates' vocal repertoires is significant to animals is still subject to debate. ${ }^{1}$ Because of a strong genetic determinism, their acoustic variability was long considered to be limited to maturational changes. ${ }^{1,2}$ New findings, although still limited to a few nonhuman primate species, illustrate to some extent vocal plasticity in this group. ${ }^{1}$ Interestingly, an exceptional level of variability has been found in call types that are usually produced as part of exchange bouts between individuals and that are associated with an affiliative function (e.g., pygmy marmosets, ${ }^{3}$ Japanese monkeys, ${ }^{4}$ and chimpanzees $\left.^{5}\right)$. On the contrary, alarm calls have been described as fixed stereotyped structures (e.g., vervet monkeys ${ }^{6,7}$ ).

Snowdon et $a .^{8}$ suggested that flexibility may occur more in higher social calls (e.g., affiliative and agonistic calls) that may require more adaptation to partners' calls and that therefore a higher level of variability should be found in these calls than in lesser social calls targeting the whole group rather than a specific group mate (e.g., alarm calls). Affiliative calls of several non-primate species vary among individuals supporting identity and social-category recognition (e.g., horses $^{9}$ and seals ${ }^{10}$ ), whereas alarm calls appear stereotyped, carrying non-social referential messages like predator type (e.g., suricates ${ }^{11}$ and marmots ${ }^{12}$ ). Owren and Rendall ${ }^{13}$ proposed an alternative hypothesis suggesting a structure-function relationship. Acoustic variability would be shaped by

\footnotetext{
a) Author to whom correspondence should be addressed. Electronic mail: alban.lemasson@univ-rennes1.fr
}

functions aimed directly at inducing changes in listeners' affect through some particular acoustic properties (notably noisy calls with repeated pulses) or by using calls as individually distinctive vehicles of listener associative learning. Individual distinctiveness would thus be stronger in calls inducing an affective response conditioned by the history of positive and/or negative past encounters between sender and listener.

Here, the hypotheses of Snowdon et al. and Owren and Rendall were tested by analyzing female Campbell's monkeys' (Cercopithecus campbelli campbelli) vocal repertoires. This species is particularly appropriate for this study: (1) because of the density of their rainforest habitat, their social communication relies predominantly on vocal rather than visual signals; and (2) since they live in harem groups, their social organization is based primarily on female-female interactions, which are mainly affiliative and include a high proportion of cohesion-contact call exchanges. ${ }^{2,14,15}$ Nevertheless, although guenon males' loud calls have been well studied (e.g., vocal sac, referential communication, and call combination), ${ }^{2,16-18}$ few reports describe female short-range intra-group signals. ${ }^{19,20}$ Given the characteristics of the Campbell's monkeys social system, it can be expected a stronger and a more subtle social influence on the level of acoustic variability in females than in males. Indeed, recent studies of Campbell's monkeys showed that, at least for one affiliative call, a given female can produce several acoustic variants, some of which are shared with some preferred group members. ${ }^{21,22}$ Playback experiments revealed that this acoustic variability was meaningful for individuals. ${ }^{23}$ Moreover, most of the female calls are soft and difficult to record under natural conditions. Also, observations at the individual level in their visually 
dense habitat are difficult. Thus, this acoustic comparison was based only on standardized recordings from captivity.

In the present study, the degree of structural (intra- and inter-individual) variability of the different calls of the repertoire of adult female Campbell's monkeys, varying in age and belonging to different matrilines, was evaluated. The problem in studying female guenon communication lies in the presence of their repertoire of sounds of very low intensity and of their ability to produce calls with their mouths closed, which makes it difficult to identify callers even in captivity. Precise measurements, based on high quality spectrograms, were required to test our hypotheses. Therefore, an original telemetric technique has been developed for sound recording. The level of variability of calls, notably individual distinctiveness, was then considered in relation to their social value, inferred from the production context. This allowed us to compare a panel of lesser vs higher social, including affiliative vs agonistic, calls.

\section{METHODS}

\section{A. Subjects and housing conditions}

Campbell's monkeys (Cercopithecus c. campbelli) are mostly arboreal and live in single-male groups of 10 to 20 individuals from several matrilines. ${ }^{24}$ This species is widespread in the West African rainforests. Campbell's monkeys (with one subspecies Lowe's monkey C. campbelli lowei) belong to the mona superspecies including $C$. wolfi, $C$. pogonias, and $C$. mona. Few descriptions of call structure of these species have been published and then mainly reports concern male loud calls or female alarm calls. ${ }^{16,17,24}$

The study group, which lives in captivity at the "Station Biologique de Paimpont" (Université de Rennes 1, France), included one adult male (Sirano) and the members of two matrilines, matriline 1 [adult females: Lisa (mother), Plume, Lowina, Maricopa, and Chilula; male infants: Pikachu (Lisa's son) and Togepi (Lowina's son)] and matriline 2 (sisters: Shawnee, Tilamook, and Bela). Two females were carrying an infant and in order to avoid any disturbance, and they were not equipped with a telemetric harness (see below). Thus, the repertoires of six adult females [three per matriline: Plume (Pl, 8yo), Maricopa (Ma, 5yo), Chilula (Ch, 4yo), Shawnee (Sh, 7yo), Tilamook (Ti, 4yo), and Bela (Be, 3yo)] were analyzed. These monkeys were kept in an indoor $\left(21 \mathrm{~m}^{2} \times 3 \mathrm{~m}\right)$ outdoor $\left(21 \mathrm{~m}^{2} \times 4 \mathrm{~m}\right)$ enclosure, and all recordings were made outdoors when all the group members were together. Enclosures were enriched with branches for climbing, but no vegetation impeded visibility. Two meals were given per day, i.e., fruits and vegetables in the morning and industrial monkey chows in the afternoon. Water was provided ad libitum.

\section{B. Material}

The telemetric system for sound recordings developed here was adapted from an existing technique. ${ }^{25}$ It ensured caller identification and gave clear spectrograms, discarding noise and echoes of all kinds, thus making intra- and interindividual comparisons possible. Radio-transmission enabled us to record wavering or even intention to vocalize. The system was composed of a transmitter, a receiver, and a numeric stereophonic DAT-recorder [DA-P1 (TASCAM, a division of TEAC America, USA)]. Each of the six females carried a transmitter composed of a microphone [EM123T (LEM industries, France); $\varnothing, 5 \mathrm{~mm}-\mathrm{L}, 3 \mathrm{~mm}$ ], positioned over the larynx area in a rubber collar adjusted round the neck of each individual, and an oscillator, which emitted from 90 to $130 \mathrm{MHz}$ with an oscillation frequency tuned with an adjustable capacitor, assembled on a circular printed circuit board. A lithium battery ( $3 \mathrm{~V} ; \varnothing, 14 \mathrm{~mm}-\mathrm{L}, 24 \mathrm{~mm}$; $9 \mathrm{~g})$ was connected to the oscillator in a plastic tube $(\varnothing, 2$ $\mathrm{cm}-\mathrm{L}, 6 \mathrm{~cm}$ ) covered inside by metallic paper connected to a spring in the cap. The cap could be unscrewed easily to change the battery. All these elements were fixed on a leather harness with two straps crossing the chest and the back of the subject and passing over its shoulders, adjusted by two buckles. One strap was used to hide the microphone connection and the other one for the antenna. Transmission range was approximately $50 \mathrm{~m}$ and the battery lasted approximately 45 days. The total equipment fixed on the monkey weighed about $45 \mathrm{~g}$. The receiver enabled us to record six animals simultaneously on individual frequency modulation (FM) tuners, but only two tracks were recorded at the same time, as the receiver was connected to the aforementioned stereophonic DAT-recorder.

\section{Sound recordings and analyses}

A total of 92 h 20 min of telemetric recordings covered a period of 34 days in September and October 2000. Two sessions, lasting $1 \mathrm{~h} 30 \mathrm{~min}$, were conducted every day in a rotating order that enabled the time-span between 9 AM and 6 PM to be covered for each female. Only spontaneous call productions were recorded during the routine daily activities of monkeys. A total of 9 to $19 \mathrm{~h}$ (mean, $15 \mathrm{~h} 11 \mathrm{~min} \pm 4 \mathrm{~h} 10 \mathrm{~min}$ ) of continuous recordings per individual was achieved, variations being due to occasional technical problems, enabling us to collect 99 to 465 (mean $217 \pm 62$ ) calls per individual. Five of our six subjects were recorded for at least $14 \mathrm{~h}$.

A total of 1348 spectrograms were computed and analyzed using a customized AMIGA computer program for sound analysis. ${ }^{22}$ Calls used for spectrographic analyses were digitized at a $24 \mathrm{kHz}$ sampling rate with an 8-bit amplitude resolution. The spectrographic analysis used fast-Fourier transforms (FFTs) with sizes of 256 points for each analyzed time window. Resulting spectrograms had a time resolution of $2.49 \mathrm{~ms}$ and a frequency resolution of $100 \mathrm{~Hz}$.

\section{Terminology and contextual definitions}

The following terms are used throughout the paper. ${ }^{20}$ "Call type" is a set of calls presenting a common basic acoustic structure. "Call subtype" is a subdivision of "type," a set of calls sharing several acoustic characteristics, but structurally divergent from other subtypes. "Unit" is a basic sound element of a call, two successive units within a call are always separated by a silent gap. "Repetition" concerns multi-unit calls composed of several structurally similar units emitted in succession at a regular rhythm. "Quavered" refers to the production of a trilled sound. Several acoustic parameters were measured on spectrograms (Table I, Fig. 1). 
TABLE I. Acoustic measurements.

\begin{tabular}{|c|c|c|}
\hline Class of sound & Measurement & $\begin{array}{l}\text { Abbreviation } \\
\quad \text { (unit) }\end{array}$ \\
\hline \multirow[t]{4}{*}{ All calls } & Dominant frequency $^{\mathrm{a}}$ & $F \max (\mathrm{Hz})$ \\
\hline & Fundamental frequency ${ }^{\mathrm{b}}$ & $\begin{array}{r}F 0 \text { start, } F 0 \text { top, } \\
F 0 \text { end }(\mathrm{Hz})\end{array}$ \\
\hline & $\begin{array}{l}\text { Amplitude of the frequency } \\
\text { modulation }\end{array}$ & $\operatorname{Amf}(\mathrm{Hz})$ \\
\hline & Duration & $D(\mathrm{~ms})$ \\
\hline \multirow[t]{2}{*}{ Multi-unit calls } & Number of units & $\mathrm{NbU}$ \\
\hline & $\begin{array}{l}\text { Interval between two } \\
\text { successive units }\end{array}$ & Dinter (ms) \\
\hline \multirow[t]{2}{*}{ Quavered calls } & $\begin{array}{l}\text { Amplitude of the frequency } \\
\text { modulation of an oscillation }^{c}\end{array}$ & Amfosc $(\mathrm{Hz})$ \\
\hline & $\begin{array}{l}\text { Duration between submits of } \\
\text { two successive oscillations }\end{array}$ & Dosc (ms) \\
\hline
\end{tabular}

${ }^{\mathrm{a} C a l c u l a t e d}$ automatically using the amplitude spectrum.

${ }^{\mathrm{b}}$ Measured at different points of the frequency modulation.

${ }^{\mathrm{c}}$ Selected in the middle and the most intense part of the call.

Brief contextual descriptions of each call subtype are also given throughout Sec. III in order to estimate the social value of the calls in terms of association with aggressive vs affiliative interactions or communication at the group vs individual level. Call contexts were determined using previous studies of this species ${ }^{14,15,21,22,24}$ and of closely related species (mona superspecies) ${ }^{2,18,20}$ in addition to some data issued from a complementary set of $42 \mathrm{~h}$ of focal observations. ${ }^{26,27}$ The detailed method of this contextual analysis and the main conclusions have already been published. ${ }^{26}$ This analysis consisted of extracting statistically the major behavioral units displayed while, or immediately before, calling and the eliciting external events associated with each call type based on a collection of 243 contextual detailed and varied items. Among the most representative items, several concerned "lesser social" categories (behaviors: vigilant posture, visual exploration of the environment, and run down to take a food item; events: sudden noise, human/ bird/cat/dog/horse passing by) and other items concerned "higher social" categories, either less- (move while staring at a group mate and forage for food near a group mate) or highaffiliative (peaceful approach, touch, and groom) and either agonistic (behaviors: threat mimic, physical attack, and chase, events: conflict involving other group mates or neighboring cage groups) or intermediary (approach while staring at the male and displaying submission).

\section{E. Statistical analyses}

One-way analyses of variance (ANOVA) evaluated intraand inter-individual variability and tested whether the six females differed for each acoustic parameter. This method is a classic bioacoustic method. ${ }^{28}$ Differences between individuals were then tested in relation to age and matriline. Nonparametric statistical tests evaluated correlations (Spearman tests) and compared groups (Mann-Whitney tests). The level of inter- and intra-individual variability was estimated by the coefficient of variation $(\mathrm{CV} \%=$ standard deviation $/$ mean $*$ $100)$, which is a statistical measure of dispersion. As it gives relative variations, it allows comparisons of data sets that have different units, e.g., duration and frequency. ${ }^{28}$ Then, a PIC (potential for individual identity coding) index was calculated. ${ }^{29} \mathrm{PIC}=\mathrm{CVinter} /$ mean of CVintra (CVinter $=$ betweenindividual coefficient of variation, $\mathrm{CV}$ intra $=$ within-individual coefficient of variation). When a PIC value for a given call is $>1$, this call presents individual differences.

The fact that the pre-defined subtypes were clearly stereotyped and did not represent gradations of a single type had to be controlled. Gradation was absent when measures for two subtypes could be discriminated statistically. Wilcoxon tests compared two sets of values representing two given subtypes, based on some critical frequency and the temporal parameters. Calls were selected randomly to have the same number of measures per female for each subtype.

\section{RESULTS}

A classification of the different call types of the (poorly known) female Campbell's monkeys' repertoire was elaborated from a structural viewpoint (based on Gautier's classification on related guenon species $)^{2,20}$ and co-validated by contextual reports. $^{2,18,20,24,26,27}$ Thus, based on several criteria (e.g., number of units, rhythm of repetition, richness in harmonics, and shape of frequency modulation), the females' calls were divided into three major categories, including ten call types including four of which types could be divided into two to six subtypes (Fig. 2).

(1) Category 1: calls with successive repetitive units emitted either at a slow [repetitive slow atonal (RSA), repetitive slow tonal (RST) with, respectively, atonal and tonal units)] or a rapid [repetitive rapid chevron (RRC), repetitive rapid ascending (RRA) with, respectively, chevron-shape and ascending frequency modulation)] rhythm. RRA included two subtypes (RRA1/2= small/large number of units).

(2) Category 2: either atonal [single atonal (SA)] or tonal [single trill (ST) - high-pitched and quavered, single harmonic long (SHL) - rich in harmonics, low-pitched and long, single harmonic ( $\mathrm{SH})$ - rich in harmonics and short] single-unit calls. Two SH (SH1/2=low-pitched/descending frequency modulation) and ST (ST1/2=long/short duration) subtypes were found.

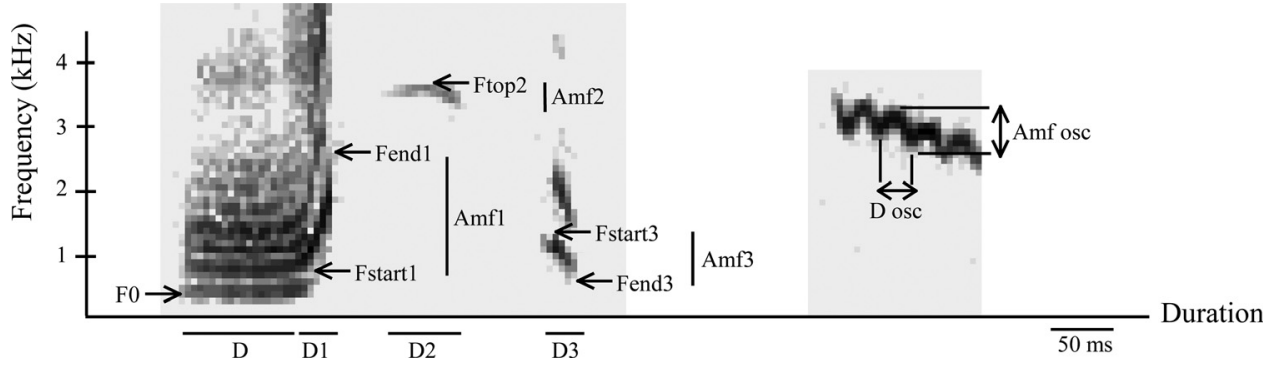

FIG. 1. Examples of acoustic measurements. The $\mathrm{CH} 5$ call subtype (left) is composed of a first lowpitched portion and a second highpitched portion divided into three parts: ascending (part 1), middle (part 2), and descending (part 3). Each portion/part was measured. The ST1 subtype (right) is quavered and oscillations are measured as shown. 


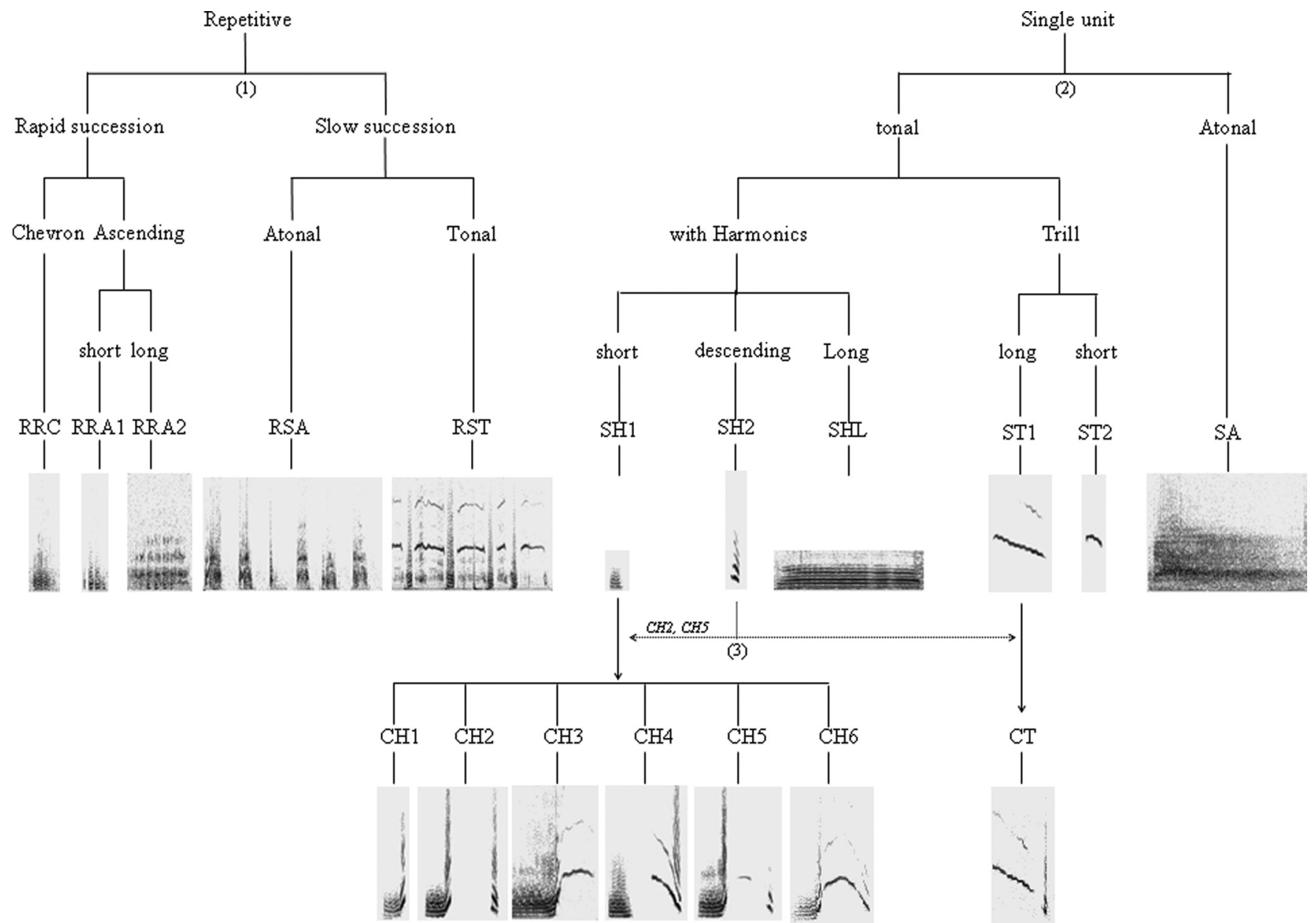

FIG. 2. Call classification. Call type names: RRC, RRA, RSA, RST, SH, SHL, ST, SA, CH, and CT.

(3) Category 3: combined calls resulting from complex associations of several aforementioned structures and other structures [combined trill (CT)—association by transition of ST and SH2 structures, combined harmonic (CH) - merged association of SH and a complex highpitched "arch-shape" structure]. Six CH subtypes corresponding to either "complete" $(\mathrm{CH} 6)$ or "broken" $(\mathrm{CH} 1$ to CH5) calls were distinguished. Only some portions of the general "arch" observed in complete calls were maintained in broken calls. The arch was divided into three portions: ascending (part 1), middle (part 2), and descending (part 3) (Fig. 1). Broken calls were divided into five subtypes according to the remaining portions (ascending: $\mathrm{CH} 1, \quad$ ascending + descending: $\mathrm{CH} 2$, ascending + middle: $\mathrm{CH} 3$, middle + descending: $\mathrm{CH} 4$, and ascending + middle + descending: $\mathrm{CH} 5$ ).

Although the majority of call types and subtypes were present in the repertoires of all the females (e.g., RRA1, SH1, and $\mathrm{CH} 4$ ), some, rarely produced, were emitted by only one or two females (e.g., RRC and RSA). The rarity of these calls seemed to be related to context (e.g., agonism) or female characteristics, such as age. For example, as Campbell's monkeys very rarely interact agonistically, ${ }^{14}$ this influenced the frequency of emission of aggressive RRC calls (see below). RSA, RST, SA, and SHL calls were extremely rare calls and discussed below in Sec. III E. "Vocal activity" decreased significantly with females' age only for $\mathrm{CH}$ calls (Spearman correlation: $r s=-0.97, n=6, p<0.05)$. No age differences $(0.93>p(\mathrm{CH} 1$ to $\mathrm{CH} 6)>0.16)$, but significant individual preferences (Mann-Whitney: $U=0.30, \quad p<0.01$ ), were observed in the propensity to emit the different $\mathrm{CH}$ subtypes.

\section{A. Lesser social calls and higher social agonistic calls: Calls with rapid repetitive units}

Two main types were distinguished, RRC and RRA, that had been described, respectively, as threat calls (also named type 4) and alarm calls or sneeze (also named type 1) by Struhsaker, ${ }^{18}$ Gautier and Gautier-Hion, ${ }^{2}$ and Gautier ${ }^{20}$ in $C$. mona, $C$. lowei, and $C$. pogonias (belonging to the mona super-species), and by Ouattara et al. ${ }^{24}$ in wild C. campbelli. Observations of captive Campbell's monkeys confirmed that RRC was associated only with aggressive behavior (i.e., threatening or attacking a group member). ${ }^{27}$ Two subtypes of RRA calls were distinguished. RRA1 was characterized by a series of 1 to 5 units generally ( $75 \%$ of times) preceded by a shorter and higher pitched introductory unit. RRA2 was characterized by a series of 4 to 10 units, very low in intensity (not audible beyond $5 \mathrm{~m}$ ). RRA2 calls lasted twice as long as RRA1 calls (Wilcoxon test: $D: z=4.148, \mathrm{NbU} z=5.35$, $n=24, p<0.01)$ and were higher-pitched at the peak of maximum energy ( $F \max : z=4.128, p<0.01)$. In captivity, RRA1 

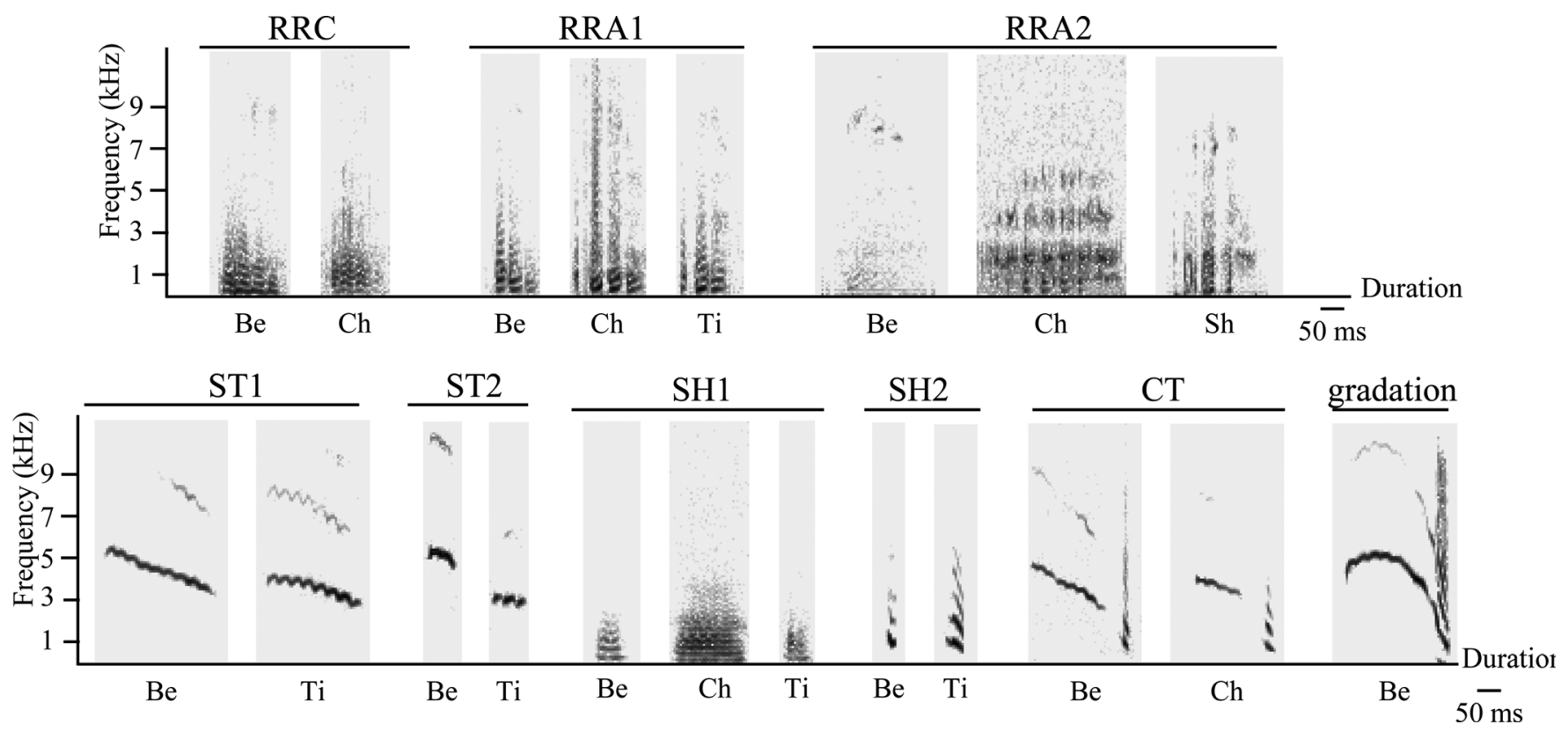

FIG. 3. Sonograms of RRC, RRA, ST, SH, and CT types. Upper sonograms: RRC type recorded from two females (Be and Ch), examples of RRA1/2 subtypes. Lower sonograms: examples for females often producing the ST1/2, SH1/2 subtypes, CT type (association by transition of ST1 and SH2 subtypes), one example of potential gradation from the CT type.

was associated with a "general vigilance," when a danger had been perceived (e.g., sudden unusual noise and animal passing by) or when descending briefly to the ground to take some food, whereas RRA2 was a "human presence alert."24,26,27

RRC was a rare call type $(N=18)$ emitted only by two females $(\mathrm{Be}, \mathrm{Ch})$, whereas RRA calls were frequently produced by all (RRA1, $N=195)$ or all but one (RRA2, $N=25)$ females (Fig. 3). The inter-individual variability of both RRC and RRA calls was higher than their intra-individual variability for all frequency and temporal parameters (Appendix A). Some differences in frequencies seemed to be related to age: older females produced calls with lower frequencies (Spearman correlation: F0start: $r s=-0.448$, Amf: $r s=-0.131, F \max : r s=-0.124, n=6$ females, $p<0.01$ ). No differences between matrilines were found.

Intra-individual variability of several features, e.g., fundamental frequency of RRC $(\mathrm{CV}=5.5 \%)$ and unit duration of RRA1 (CV=2.1\%) were remarkably low, but it was relatively high for others, e.g., inter-unit duration $(\mathrm{CV}=45.6 \%$ RRA1 and $151.2 \%$ RRC) and energy distribution ( $F \max$ : $\mathrm{CV}=55.4 \%$ RRA1 and $69.8 \%$ RRA2).

\section{B. Higher social intermediary affiliative calls: Single unit calls}

ST and SH calls were the two main types distinguished. ST and SH have been described, respectively, as contact calls (also named type 6, frequent in the repertoire of immatures) and cohesion calls (also named type 2) by Gautier and Gautier-Hion ${ }^{2}$ and Gautier ${ }^{20}$ for C. pogonias. However, captive adult female Campbell's monkeys emitted ST calls in a context of "contact seeking (mostly toward the adult male) while displaying submission," whereas SH calls were associated with a context of "maintenance of a vocal contact during locomotion."26,27 Two ST subtypes were distinguished by their duration (ST1 $217 \pm 98 \mathrm{~ms}$, ST2 $64 \pm 19 \mathrm{~ms}$, Wil- coxon test: $z=2.201, n=7, p<0.05$ ). Occasionally ( $8 \%$ of times), ST1 calls presented a discontinuity with a break on F0 of $52.3 \mathrm{~ms}$ on average. Two SH subtypes were distinguished as their frequency modulation and frequency parameters differed (SH1-quavering profile and $\mathrm{SH} 2-$ decreasing frequency modulation).

The ST type was frequently produced by the youngest females $(\mathrm{Be}, N=51$; Ti; $N=22)$ but very rarely by the oldest females (Sh, $N=1$; Pl $N=1$; Fig. 3 ). The SH type was frequent, produced by all (SH1, $N=111)$ or half ( $\mathrm{SH} 2$, $N=16$ ) of the females (Fig. 3). Inter-individual variability was higher than intra-individual variability for most parameters (Appendix B). Inter-individual differences of frequency parameters appeared to be correlated with age (Spearman correlation, ST1: $F \max : r s=-0.763$, Fstart: $r s=-0.820$, Fend: $r s=-0.756, n=4$ females; SH1: F0: $r s=-0.711$, $n=6$ females, $p<0.01$ ), and differences of SH1 temporal parameters existed between matrilines, matriline 1 members emitted longer calls (Mann-Whitney: $U=1652$, $n 1=47, n 2=57, p<0.01$; Fig. 4). Quavering profiles (i.e., oscillations' shape) of subjects also differed. All ST and SH parameters revealed a high intra-individual stability (except SH2's duration).

\section{Higher social affiliative calls: Combined calls}

$\mathrm{CT}$ and $\mathrm{CH}$ calls were the two types distinguished. Only $\mathrm{CH}$ had been described previously as cohesion-contact calls (also named type 2-6 or "OOO" calls) by Struhsaker, ${ }^{18}$ Gautier and Gautier-Hion, ${ }^{2}$ and Gautier. ${ }^{20}$ These calls were supposed to be produced in various social contexts. Captive female Campbell's monkeys emitted preferentially these calls in two peaceful and relaxed affiliative contexts: "cofeeding," i.e., eating peacefully in close proximity, and "seeking physical contact." ${ }^{26,27} \mathrm{CH}$ calls were never associated with agonism. They were usually produced within 

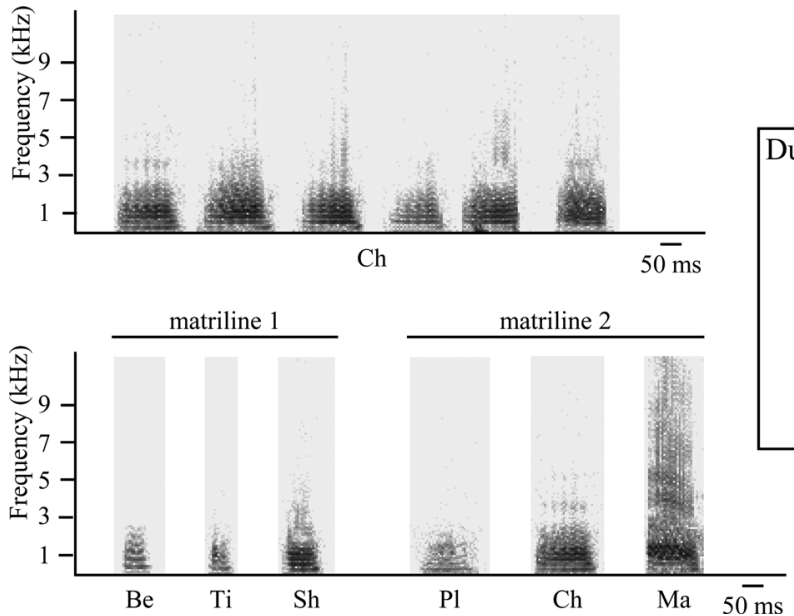

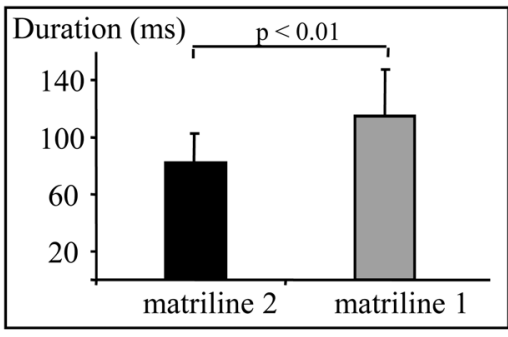

FIG, 4. Intra- and inter-individual variability in SH1 calls. Several sonograms illustrate intra- (upper calls, examples of Chilula's calls) and inter-individual (lower calls) variability in SH1 structures. Matrilines differed significantly in call duration. Maricopa's structure was intriguingly rich in harmonic distribution compared to that of the other females. affiliative conversation-like vocal exchanges between particular preferred social partners. ${ }^{14,15,23}$

CT type calls were rare $(N=11)$ and emitted only by the three youngest females ( $\mathrm{Be} N=6$, Ti $N=3$, $\mathrm{Ch} N=2$ ). They are the result of the combination of a ST (1 or 2) and a SH2 call, separated, on average, by a $60 \mathrm{~ms}$ interval (Fig. 3). No inter-individual comparison has been made given the low number of calls. Other very rare calls were recorded and seemed to be gradations of this type (Fig. 3).

In contrast, $\mathrm{CH}$ type calls were the most frequently produced, and emitted by all females. These calls correspond to a combination between a SH1 subtype and a higher-pitched part (Fig. 5). No significant differences were found between the acoustic structure of SH1 produced as an isolated call and as a combined call (Wilcoxon test, F0/D/Amfosc/Dosc: $p>0.05)$. The important variability of the frequency modulation of the high-pitched part led us to define six different subtypes that were clearly distinguishable and repeatable.

(1) $\mathrm{CH} 1 \quad(N=313)$ : brief $(<40 \mathrm{~ms})$ ascending frequency modulation, produced by all females except Sh.

(2) $\mathrm{CH} 2(N=175)$ : brief ascending frequency modulation followed by a long ( $>100 \mathrm{~ms}$ ) interval break and then followed by a brief descending frequency modulation similar to the structure of $\mathrm{SH} 2$, produced by all females except Ma.

(3) $\mathrm{CH} 3(N=82)$ : long $(>100 \mathrm{~ms})$ ascending and curved frequency modulation reaching frequencies around $4 \mathrm{kHz}$. A total of $76 \%$ of the calls presented a very small decreasing second part and $60 \%$ of the calls presented a short interval break during the ascending phase, lasting $13 \mathrm{~ms}$ on average. Only three females (Be, $\mathrm{Ti}$, and $\mathrm{Ch}$ ) emitted this subtype.

(4) $\mathrm{CH} 4(N=64)$ : in this call, the $\mathrm{SH} 1$ structure was not merged with the long $(>80 \mathrm{~ms}$ ) descending and curved frequency modulation, as a long interval break $(>100$ ms) occurred between the two structures. A total of $17 \%$ of the calls presented a small ascending curved part. All females presented this subtype.

(5) $\mathrm{CH} 5(N=123)$ : similar to $\mathrm{CH} 2$ with a small curved frequency modulation added in the middle of the interval pause, produced by all females except Ma.

(6) CH6 $(N=91)$ : complete arch. The ascending first part was shorter than the descending second part. All females, except Ma, produced this subtype.

Pairs of subtypes were compared on the basis of critical parameters to investigate whether these subtypes could be interpreted as stereotypical structures or were the result of a graded system (Fig. 6). The six $\mathrm{CH}$ subtypes appeared to be clearly stereotyped. Some subtypes could be distinguished on the basis of the first ascending part of their structure, both in frequency and duration $(\mathrm{CH} 1, \mathrm{CH} 2, \mathrm{CH} 5$ vs $\mathrm{CH} 3$; $\mathrm{CH} 4$ vs $\mathrm{CH6}$ ), others differed in their last descending part ( $\mathrm{CH} 1$, $\mathrm{CH} 2, \mathrm{CH} 5$ vs $\mathrm{CH} 4 ; \mathrm{CH} 3$ vs $\mathrm{CH} 6)$ and others differed in the duration of the silence break ( $\mathrm{CH} 2$ vs $\mathrm{CH} 5)$.
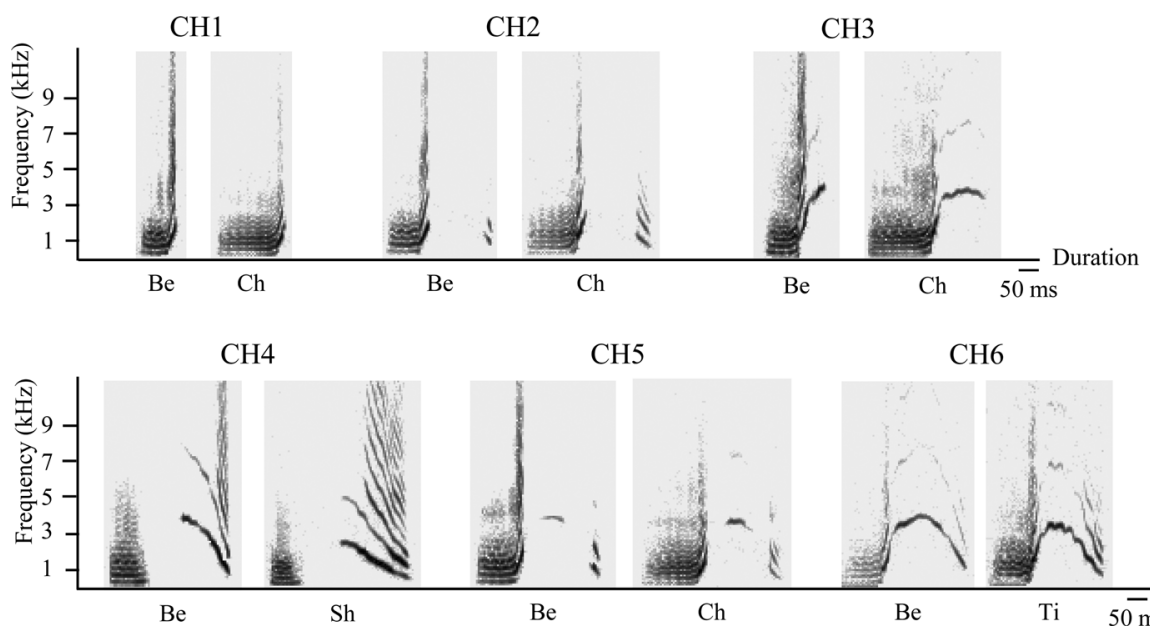

CH5

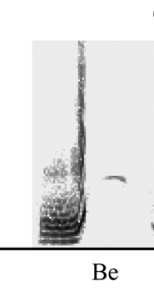

CH6

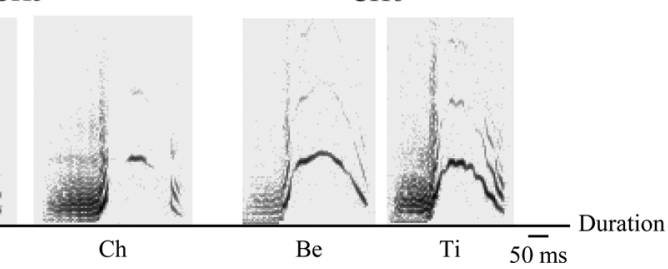

FIG. 5. Sonograms of $\mathrm{CH}$ types. For each of the six $\mathrm{CH}$ call subtype, two sonograms are illustrated including at least always the same individuals Bela. 
Inter-individual variability of all subtypes was greater than their intra-individual variability (Appendix C). Frequency parameters tended to decrease with age (e.g., start and end frequencies of each call part, Spearman correlations: $-0.88<r s<-0.48, p<0.01$ for all $\mathrm{CH}$ subtypes). Matrilines could be distinguished on the basis of duration. Matriline 1 members emitted longer $\mathrm{CH} 1$ and $\mathrm{CH} 3$ (MannWhitney: $p<0.01$; CH1: $U=8853 \mathrm{n} 1=76 \mathrm{n} 2=79$, CH3: $U=1723 \mathrm{n} 1=52 \mathrm{n} 2=29)$ but shorter $\mathrm{CH} 2$ and $\mathrm{CH} 5$ $(p<0.01$; CH2: $U=5338 \mathrm{n} 1=58 \mathrm{n} 2=75$; CH5: $U=2599$ $\mathrm{n} 1=46 \mathrm{n} 2=32$ ) calls than did matriline 2 members.

$\mathrm{CH} 1$ subtype calls showed a higher intra-individual stability compared to the other subtypes. The degree of variability of the other subtypes depended on the portion of the call measured. The highest variability was observed at the end of calls, i.e., part 3 [e.g., $\mathrm{CH} 2$ : $\mathrm{CV}(\mathrm{D})=65.4 \%$, CH3: $\mathrm{CV}(\mathrm{Amf})=85.9 \%, \mathrm{CH} 4: \mathrm{CV}(\mathrm{Amf})=68.1 \%, \mathrm{CH} 6$ : $\mathrm{CV}(\mathrm{Fend})=62.3 \%$ ]. Moreover, frequency modulation of CH6 calls presented important variations, i.e., shape of the high-pitched arch. That led us to define, in a parallel study, structural variants on the basis of the calculation of an acoustic similarity index and cluster analysis. Each female had, in her own repertoire, at one time, one to four variants that could be shared with other members on the basis of preferential social bonds. ${ }^{21,22}$ Another level of complexity in the variability of CH6 calls was the presence/absence of quavering in their upper portion: $54 \%$ of the calls were quavered, one female produced all-quavered calls, one female produced allnon-quavered calls, and three females produced both kinds.

\section{Stereotypy and variability in the different calls: Related to social function?}

An overall view of the level of variability of the different call types (all subtypes pooled) revealed a strong relationship between their "social affiliative value" and their degree of variation (Table II and Fig. 7). The coefficients of variation were the lowest for the rapid repetitive calls observed in threat contexts and presenting no subtype. Although individuality did emerge $(\mathrm{PIC}>1)$ in these calls, its level was much lower than for other call types. The other extreme was found for the affiliative $\mathrm{CH}$ calls that showed large variations in their frequency modulation, and, on this basis, six different subtypes were defined, as well as the largest coefficients of variation, especially in inter-individual comparisons. All the parameters of these calls were highly individual. Interestingly, number of subtypes, degree of variability and level of individuality of socially "intermediate" calls (non aggressive and non affiliative) presented intermediate values. These findings strongly support the idea of a relationship between social affilliative values and vocal information through structural variability. Additional findings indicating that $\mathrm{CH}$ calls could also support a complex system of vocal sharing, through subtle variation in frequency modulation reflecting dyadic affinities, ${ }^{21-23}$ show how call types may carry combined information on individual identity and social characteristics.

\section{E. Other rare female calls}

Two other call types could be distinguished in the first category but were only recorded in Be. RSA type call $(N=1)$
Dyadic sub-type comparison
$\mathrm{CH} 1$

$$
\not
$$

$\mathrm{CH} 2$

$$
\mathrm{CH} 2
$$

$\mathrm{CH} 2$
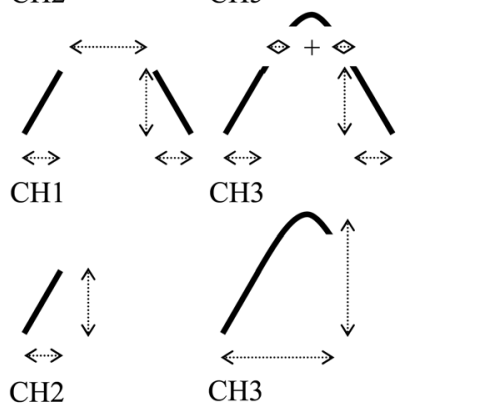

$\mathrm{CH} 2$

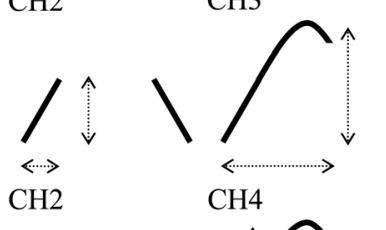

$\mathrm{CH} 2$

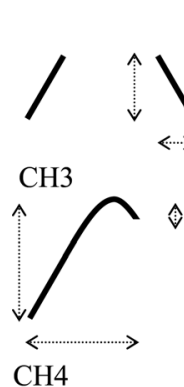

$\mathrm{CH} 4$

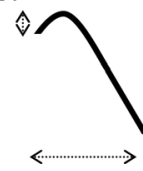

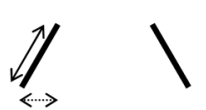

CH5
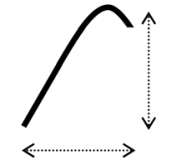

$\mathrm{CH} 3$

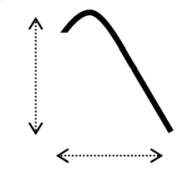
CH6

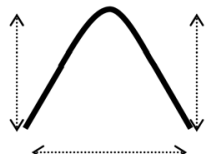
CH6

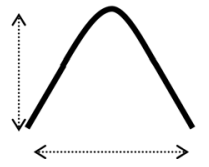

D part1 $(-0.24 / 0.81)$

Slope part1 (-1.52/0.13)

D part1 $(0.48 / 0.63)$

Fstart part3 $(-0.29 / 0.77)$

Fend part3 $(-1.64 / 0.10)$

D part3 $(1.05 / 0.30)$

Amf part3 (0.38/0.71)

Break duration $(7.03 / * * *)$

D part1 $(-7.89 / * * *)$

Amf part1 $(-7.91 / * * *)$

Ftop part2 $(-7.91 / * * *)$

D part1 $(-7.13 / * * *)$

Amf part1 (-7.17/***)

Ftop part2 $(-7.18 / * * *)$

Fstart part3 $(-5.07 / * * *)$ D part3 $(-4.56 / * * *)$

Amf part3 (-3.30/***)

Amf part1 (1.60/0.054)

Ftop part2 (1.49/0.14)

Fend part3 $(6.86 / * * *)$

Amf part3 (-6.85/***)

Dcall $(-6.86 / * * *)$

Amf part1 (-5.99/***)

Ftop part2 $(-3.67 / * * *)$

Fend part3 (1.71/0.09)

Dcall $(-5.90 / * * *)$
FIG. 6. Structural comparison of $\mathrm{CH}$ subtypes. To test if $\mathrm{CH}$ subtypes were graded or stereotyped, comparisons were done, using key parameters, between pairs of subtypes which were structurally close. A diagram of calls on the left illustrates some of the specific comparisons. The key parameters are listed on the right with the $z / p$ values of the Wilcoxon test in brackets $(* * * p<0.01)$.

was a rhythmic succession of atonal and high-pitched very noisy units always produced by a female when she was physically attacked (bitten, grasped) by a group member. ${ }^{27}$ This call was defined as a gecker call. ${ }^{20,30}$ RST type call $(N=2)$ was a succession of alternatively high- and low-pitched tonal units. The RST type is structurally close to the "crying" of infants (pers. obs.) and has not been defined previously.

Two other call types could be distinguished in the second category. SA type call was a high-pitched and noisy call, only produced by females being severely attacked by a neighboring group or when being captured by humans. This call had been defined as a scream by Gautier and Gautier-Hion, ${ }^{2}$ Gautier, ${ }^{20}$ and Struhsaker. ${ }^{18}$ SHL type call resembled a very long SH1 call and was only heard when adult females were isolated from their group. This type seemed to be much more frequently emitted by young individuals and was described as an isolation call (or type 3 ) by Gautier ${ }^{20}$ in C. pogonias. 


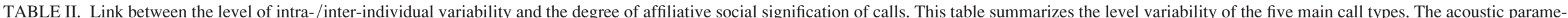

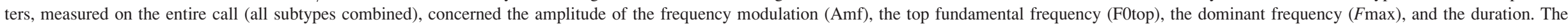

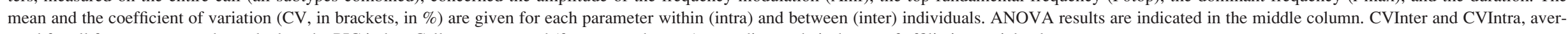
c. aged for all factors were used to calculate the PIC index. Calls are presented (from top to bottom) according to their degree of affiliative social value.

\begin{tabular}{|c|c|c|c|c|c|c|c|c|c|c|c|c|c|c|c|c|c|c|}
\hline \multirow{2}{*}{$\begin{array}{l}\text { Call } \\
\text { type }\end{array}$} & \multirow{2}{*}{$\begin{array}{l}\mathrm{Nb} \text { of } \\
\text { subtypes }\end{array}$} & \multicolumn{3}{|c|}{$\begin{array}{c}\text { Frequency modulation } \\
\text { amplitude }\end{array}$} & \multicolumn{3}{|c|}{$\begin{array}{l}\text { Top fundamental } \\
\text { frequency }\end{array}$} & \multicolumn{3}{|c|}{ Dominant frequency } & \multicolumn{3}{|c|}{ Total duration } & \multicolumn{3}{|c|}{$\begin{array}{l}\text { All parameters } \\
\text { combined }\end{array}$} & \multirow{2}{*}{$\begin{array}{l}\text { Frequency } \\
\text { modulation }\end{array}$} & \multirow[b]{2}{*}{ Context } \\
\hline & & Inter & $p$ & Intra & Inter & $p$ & Intra & Inter & $p$ & Intra & Inter & $P$ & Intra & CVInter & CVIntra & PIC & & \\
\hline RRC & 0 & $378(11.7)$ & - & $372(10.7)$ & $539(7.1)$ & a & $534(5.5)$ & $446(130.4)$ & $\mathrm{a}$ & $537(7.9)$ & $100.1(33.5)$ & - & $94.8(36.8)$ & 45.7 & 20.3 & 2.25 & - & Threat \\
\hline RRA & 2 & $416(81.6)$ & $-^{\mathrm{a}}$ & $398(21)$ & $630(82.6)$ & $-^{\mathrm{a}}$ & $606(14.7)$ & $881(123.1)$ & $\mathrm{b}$ & 905 (71.7) & $138.3(77)$ & $-^{a}$ & $140.8(30.2)$ & 91.1 & 34.4 & 2.65 & & Alarm \\
\hline ST & 2 & $1349(44.7)$ & - & $1381(43)$ & $4519(61.9)$ & a & $3966(14)$ & $4036(73.6)$ & $\mathrm{a}$ & $3395(18.6)$ & $200.9(111)$ & $\mathrm{c}$ & $301.5(30.8)$ & 72.8 & 26.6 & 2.74 & $-/+$ (quavering) & Appeasement \\
\hline SH & 2 & $346(102.5)$ & a & $361(29.5)$ & $439(232.9)$ & a & $500(59.4)$ & $885(36.5)$ & - & $879(34.3)$ & 90.5 (159) & a & $84.9(31.1)$ & 132.7 & 38.6 & 3.44 & $-/+$ (quavering) & Cohesion \\
\hline $\mathrm{CH}$ & 6 & $1914(188.1)$ & a & $1565(53.1)$ & $2790(207.7)$ & a & $2475(34.1)$ & $2143(241.9)$ & a & $1906(53.2)$ & 152.5 (272.6) & a & $142.4(60.3)$ & 227.6 & 50.2 & 4.53 & $\begin{array}{c}+ \text { (quavering, } \\
\text { arch shape) }\end{array}$ & Affiliation \\
\hline
\end{tabular}

\section{— denotes not significant.}

${ }^{\mathrm{a}} p<0.001$.

${ }^{\mathrm{b}} p<0.05$.

${ }^{\mathrm{c}} p<0.01$.
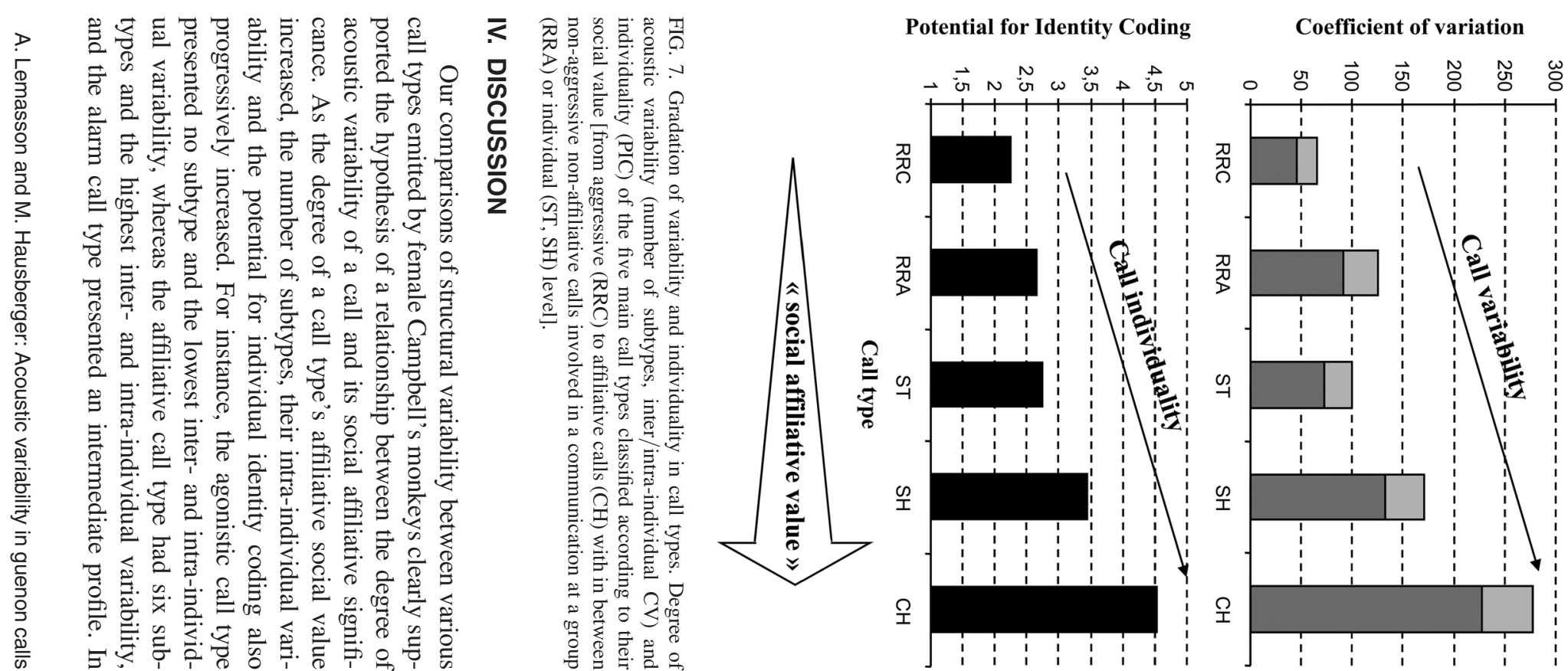

Number of subtypes

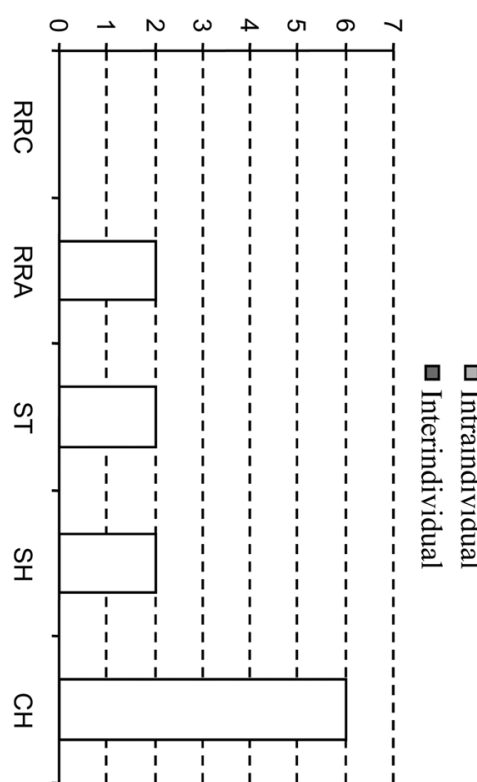


addition, this study is the first to give a full description of the vocal repertoire of females of this species.

Our study supports partially the hypothesis of Snowdon et al. in a sense that lesser social calls presented a limited variability, ${ }^{8}$ but not all higher social calls were strongly variable, as threat and contact calls presented opposite patterns. Our study also supports Owren and Rendall's hypothesis because the lowest level of individual distinctiveness was found in calls with particular acoustic properties like repeated pulses and noisiness, whereas calls involved in affiliative interactions were highly variable. ${ }^{13}$ More interestingly, the more a call was associated with an affiliative function, the more it was flexible and individually distinctive. Further investigations involving more species are now needed to determine whether the degree of affiliation is a universal determinant predicting acoustic variability. It would be interesting to compare species with a relatively tolerant social organization, like ours, with other more despotic species.

Decomposing the vocal repertoire into different categories and sub-categories is common in bird and marine mammal studies. ${ }^{31}$ Starling songs are grouped in notes or motifs for instance presenting several functional sub-categories. ${ }^{31}$ Here, the vocal repertoire was based on three structural levels: call type, subtype, and variant. This organization is rarely described in nonhuman primates.

A first hypothesis predicts that categories are sometimes difficult to determine in nonhuman primates. Several primate species, notably those living in open areas, can ensure the transmission of a given message by using multi-modal communication and present a systematically graded vocal repertoire with hardly classifiable calls. ${ }^{32}$ They are opposed to forest species that rely mostly on calls to communicate despite strong sound degradation during propagation. ${ }^{33}$ These species possess a more discrete repertoire with a limited number of reliable "stereotyped call" types, thus reducing the risk of message confusion. ${ }^{19}$ Nevertheless, some forest species possess a graded and large repertoire that has been explained by group size and the frequency of close interactions. ${ }^{34,35}$ Here, the level of variability was neither uniformly nor randomly distributed over the whole repertoire of a given species, i.e., some call types being more variable than others in relation to their social context of occurrence. The social value of a call type's function influenced its subsequent subdivisions. The most subtypes were found in the affiliative $\mathrm{CH}$ call type. Our results show that these different subtypes coexist in one individual and neither gradations between subtypes nor age effects in the frequency of production of the different structures were evidenced. Concerning alarm call subtypes, inter-population divergences can be found due to differences in environments. The human alarm described here does not exist in wild Campbell's monkey populations for instance. ${ }^{24}$ Moreover, if the different subtypes exist in all individuals of a given population, this is not true at the variant level (within subtype) as the structuration of variants is socially controlled. A CH6 given variant is only shared by a limited number of preferential partners. ${ }^{21,22}$

A second hypothesis predicts that as nonhuman primates calls are often considered as predominantly genetically determined this a priori fixity would discourage people from investi- gating acoustic variability. Conversely to alarm calls which have been intensively studied for their referential properties, $6,7,16,17,24$ nonhuman primate affiliative calls have been under-evaluated in this regard, because the large diversity of associated contexts and acoustic structures make their study more difficult. Other reports nevertheless confirm the existence of subtypes linked to different social situations in affiliative calls. ${ }^{36,37}$

An interesting question here was how a given species can "create" acoustic variability. There are two possibilities. One possibility is to have non-fixed acoustic parameters. The level of intra- and inter-individual variability of some frequency and temporal parameters was related to the call's social value. Another possibility is to use syntactic-like sound combinations. A previous work on Campbell's monkeys showed that males are able to recombine sound units or even call types to increase the number of messages delivered. ${ }^{16,17}$ For instance, males optionally add a unique suffix at the end of some call stems, thus altering the message and doubling their repertoire size. Also, potential sound combinations and affixation abilities can be evidenced in females. For instance, $\mathrm{CH}$ calls are the result of a merged association between a short low-pitched SH call (which can also be produced alone) and a high-pitch arched frequency modulation. The duration of SH calls potentially carries reliable information about matriline membership, whereas the arch shape encodes for social affinities. ${ }^{21}$ The arch shape and sharing patterns change over years following changes observed in the social network. ${ }^{22}$ Habitat is often regarded as a strong constraint on acoustic variability in primates as it influences propagation of calls. ${ }^{1,33}$ Nevertheless, no adaptative reason (neither species weight nor background noise and distortion properties ${ }^{33}$ ) can explain the presence of high-pitched short-range signals in arboreal guenons. $\mathrm{CH}$ calls present a whistle-type structure with a large frequency modulation comparable to starling or dolphin whistles also used in a process of socially biased vocal sharing, ${ }^{31}$ which is another illustration of the structure-function relationship. ${ }^{13}$

Why then does such an acoustic variability exist? Finding more variability in affiliative calls than in agonistic calls or alarm calls might be explained by the fact that affiliative communication requires potentially a much more subtle exchange of information between particular social partners. Different types of social information can be carried by affiliative calls in nonhuman primates, such as the belonging to a given social unit, ${ }^{3,5,22}$ the caller's intention to interact in a particular way, ${ }^{37}$ or the request for a vocal response. ${ }^{38}$ Campbell's monkeys are not the only primates who can modify the acoustic structure of their affiliative calls as call convergence and call matching exist in marmosets, ${ }^{3}$ chimpanzees, ${ }^{5}$ and Japanese macaques. ${ }^{4}$

Finally, another key information transmitted by calls is caller identity. This information is essential when habitat visibility is reduced or when the group is large (e.g., penguins $^{29}$ ) for the listener to adjust its behavior in consequence. However, not all call types need to carry individual identity. ${ }^{13}$ The important fact, when hearing a predator alarm call, is to adopt a protective response no matter who the caller was. Conversely, many studies stress the importance of identity coding in mother-infant communication (e.g., fur seals ${ }^{10}$ and sheeps $\left.{ }^{39}\right)$. All the main calls in the Campbell's 
monkeys' repertoire showed significant differences between individuals, which is common in primates ${ }^{40}$ and non-primates $9,29,41$ for a large diversity of calls. However, here the value of the potential for individual identity coding was clearly positively influenced by the call involvement in the within-group affiliative social life. In addition to social function, the caller-listener average distance might also influence the degree of variability. For instance, chimpanzee long-distance affiliative calls have a higher potential to encode identity than do short-distance affiliative calls. ${ }^{39}$ Here, differences between individuals were notably due to age(especially for frequency parameters, a classic observation in primates $^{2}$ and other mammals ${ }^{9}$ ) or matriline- (especially for temporal parameters, also observed in other primates ${ }^{42}$ and whales ${ }^{43}$ ) differences, but also to individual characteristics. So, even for $\mathrm{CH}$ calls involved in vocal sharing, some acoustic parameters remain characteristic of the caller enabling its identification. This has been labeled "optimal vocal sharing." 29 It is always important to be recognized as an individual even when a call is advertising its social affinities.

\section{CONCLUSIONS}

A given call type can encode, in its acoustic structure, different levels of information such as the context of a social situation (subtype), the caller identity and other social characteristics like preferential bonds. Animals might use different acoustic parameters to transmit on the one hand their identity and on the other hand the social context (see also dog barks ${ }^{44}$ and baboon grunts ${ }^{45}$ for instance). Nevertheless, all call types in a species' repertoire, according to their function, are not equivalent in this regard. The fact that some of the acoustic variability might still have been underestimated here needs to be acknowledged. No noise-related measurements and no nonlinear phenomenon have been taken into account here, as none of the previous reports on that species pointed out these traits has potentially informative. ${ }^{16,17,21,22,24}$ Nevertheless, this should be investigated in future studies as they might be another source of variability. ${ }^{46}$

\section{ACKNOWLEDGMENTS}

We thank Jean-Pierre Gautier and Klaus Zuberbühler for useful discussions.We are very grateful to Lucien Macé (C.N.E.T. Lannion, France), Philippe Bec, and Ronan Jubin for technical assistance. We thank Adrian Craig and Ann Cloarec for English-language corrections. This project received the financial support of the French ministry of research and education, the C.N.R.S. O.H.L.L. program "Origine de l'Homme, du Langage et des Langues," the ANR "ORILANG," and the "Institut Universitaire de France."

\section{APPENDIX A: ACOUSTIC PARAMETERS OF RRC AND RRA CALLS}

Means and coefficients of variation (in brackets, in \%) are given for each parameter within (intra) and between (inter) individuals. ANOVA results are indicated in the middle column. Parameters measured involved both the entire call and the unit. RRA had two subtypes: RRA1 and RRA2. RRC and RRA2 did not have any introductory unit.

Example of interpretation: no significant difference between individuals in the duration of introductory units of RRA1 calls, which were very variable within individuals $(\mathrm{CV}=44.5 \%)$, whereas all the typical unit characteristics differed significantly between individuals.

\begin{tabular}{|c|c|c|c|c|c|c|c|c|c|c|}
\hline & & \multicolumn{3}{|c|}{$\operatorname{RRC}(N=18)$} & \multicolumn{3}{|c|}{$\operatorname{RRA1}(N=163)$} & \multicolumn{3}{|c|}{ RRA2 $(N=25)$} \\
\hline & & Intra & & Inter & Intra & & Inter & Intra & & Inter \\
\hline \multirow[t]{2}{*}{ Call } & $D(\mathrm{~ms})$ & $94.8(36.8)$ & - & $100.1(33.5)$ & $132.3(18.1)$ & $\mathrm{a}$ & $128(83.4)$ & $228.9(27.7)$ & - & 231.9 (19) \\
\hline & $\mathrm{NbU}$ & $2.7(33.7)$ & $\mathrm{b}$ & $3.1(77.1)$ & $3(16.6)$ & a & $2.8(74.3)$ & $5.8(24.8)$ & - & $5.8(34.5)$ \\
\hline \multirow{3}{*}{$\begin{array}{l}\text { Introductory } \\
\text { unit }\end{array}$} & $D(\mathrm{~ms})$ & & & & $9.9(44.5)$ & - & $11.7(46.6)$ & & & \\
\hline & Dinter (ms) & & & & $19.3(19.7)$ & $\mathrm{a}$ & $23.1(108.7)$ & & & \\
\hline & $F \max (\mathrm{Hz})$ & & & & 881 (71.6) & - & $1093(80)$ & & & \\
\hline \multirow[t]{6}{*}{ Typical unit } & $\mathrm{D}(\mathrm{ms})$ & 35 (18.7) & a & $29.6(134.7)$ & $25.1(2.1)$ & $\mathrm{a}$ & $29.7(45.7)$ & $28.7(24.9)$ & $\mathrm{b}$ & $29.6(41.1)$ \\
\hline & Dinter (ms) & $2.6(151.2)$ & $\mathrm{b}$ & $4.7(210.4)$ & $10(45.6)$ & $\mathrm{a}$ & $10.1(297.5)$ & $12.1(32.3)$ & a & $11.9(96.3)$ \\
\hline & $F \max (\mathrm{Hz})$ & $539(11.7)$ & a & $423(201.8)$ & $646(55.4)$ & a & 639 (209) & $1917(69.8)$ & - & 2009 (38.1) \\
\hline & $F 0$ start $(\mathrm{Hz})$ & & & & $181(20.7)$ & a & $215(98.2)$ & $225(14.3)$ & a & $223(53.1)$ \\
\hline & $\operatorname{Amf}(\mathrm{Hz})$ & $372(10.7)$ & - & 378 (11.7) & $344(23.7)$ & a & $414(87.7)$ & 405.7 (21.6) & $\mathrm{c}$ & $405(46.9)$ \\
\hline & $F 0$ top $(\mathrm{Hz})$ & $534(5.5)$ & a & $539(7.1)$ & & & & & & \\
\hline
\end{tabular}

\footnotetext{
- denotes not significant.

${ }^{\mathrm{a}} p<0.001$.

${ }^{\mathrm{b}} p<0.05$.

${ }^{\mathrm{c}} p<0.01$.
}

\section{APPENDIX B: ACOUSTIC PARAMETERS OF ST AND SH CALLS}

ST and SH each had two subtypes (ST1/2, SH1/2). No inter-individual comparison was made for ST2 given the low number of calls. The fundamental frequency of SH1 could not be tested (?) since no variation was observed within individuals. ANOVA results are indicated in the middle column. 


\begin{tabular}{|c|c|c|c|c|c|c|c|c|c|c|c|}
\hline & \multicolumn{3}{|c|}{$\mathrm{ST} 1(N=52)$} & \multicolumn{2}{|c|}{$(N=5) \mathrm{ST} 2(N=2)$} & \multicolumn{3}{|c|}{ SH1 $(N=104)$} & \multicolumn{3}{|c|}{$\mathrm{SH} 2(N=16)$} \\
\hline & Intra & & Inter & Bela & Tilamook & Intra & & Inter & Intra & & Inter \\
\hline$F 0$ start $(\mathrm{Hz})$ & 3988 (13.1) & a & $4547(58.3)$ & $4515.8(16.7)$ & $3286.5(3.2)$ & $309(0)$ & $?$ & $306(35.4)$ & & & \\
\hline$F 0$ end $(\mathrm{Hz})$ & $2245(23.3)$ & a & $3112(76.8)$ & $3773.2(15.6)$ & 2935 (1.2) & & & & $697(23.3)$ & - & 705 (18) \\
\hline $\operatorname{Amf}(\mathrm{Hz})$ & & & & & & 0 & & 0 & $551(26.8)$ & $\mathrm{b}$ & $602(72.4)$ \\
\hline$F \max (\mathrm{Hz})$ & 3400 (18.9) & a & $4072(70.6)$ & & & 805 (36.6) & - & $846(42.4)$ & $1121(18.2)$ & - & $1135(12.4)$ \\
\hline$D(\mathrm{~ms})$ & $309.1(27.7)$ & $\mathrm{b}$ & $216.8(97.6)$ & $61.77(32.9)$ & $73.48(7.2)$ & $96.3(22)$ & a & $100.3(110.3)$ & $26(51.7)$ & - & $26.6(17.6)$ \\
\hline Amf (osc) (Hz) & $438.9(23.7)$ & $\mathrm{b}$ & $509(54.1)$ & & & $306(5.4)$ & a & 307 (20.6) & & & \\
\hline$D(\mathrm{osc})(\mathrm{ms})$ & $27.1(12.5)$ & - & $27.9(14.4)$ & & & $26(11.8)$ & a & $25.1(52.8)$ & & & \\
\hline
\end{tabular}

- denotes not significant.

${ }^{\mathrm{a}} p<0.001$.

${ }^{\mathrm{b}} p<0.01$.

\section{APPENDIX C: ACOUSTIC PARAMETERS OF CH CALLS}

$\mathrm{CH}$ type was composed of six subtypes. Several parameters were measured on each part of the high-pitched frequency modulation (part1: ascending, part2: middle, part3: descending), on the entire call and on the oscillations present at the top of some calls. ANOVA results are indicated in the middle column.

\begin{tabular}{|c|c|c|c|c|c|c|c|c|c|c|c|c|c|c|c|c|c|c|c|}
\hline & & \multicolumn{3}{|c|}{$\mathrm{CH} 1(N=156)$} & \multicolumn{3}{|c|}{$\mathrm{CH} 2(N=134)$} & \multicolumn{3}{|c|}{$\mathrm{CH} 3(N=82)$} & \multicolumn{3}{|c|}{$\mathrm{CH} 4(N=53)$} & \multicolumn{3}{|c|}{$\mathrm{CH} 5(N=80)$} & \multicolumn{3}{|c|}{$\mathrm{CH6}(N=91)$} \\
\hline & & Intra & & Inter & Intra & & Inter & Intra & & Inter & Intra & & Inter & Intra & & Inter & Intra & & Inter \\
\hline \multirow[t]{5}{*}{ Part 1} & $F$ start $(\mathrm{Hz})$ & $\begin{array}{l}627 \\
(0)\end{array}$ & $?$ & $\begin{array}{c}634 \\
(88.2)\end{array}$ & $\begin{array}{l}631 \\
(6.4)\end{array}$ & a & $\begin{array}{c}619 \\
(76.1)\end{array}$ & $\begin{array}{c}670 \\
(1.6)\end{array}$ & $\mathrm{a}$ & $\begin{array}{c}667 \\
(47.2)\end{array}$ & & & & $\begin{array}{c}623 \\
(1.8)\end{array}$ & a & $\begin{array}{c}642 \\
(38.4)\end{array}$ & $\begin{array}{c}626 \\
(5.9)\end{array}$ & a & $\begin{array}{c}648 \\
(45.5)\end{array}$ \\
\hline & Fend $(\mathrm{Hz})$ & $\begin{array}{c}1809 \\
(10.4)\end{array}$ & $\mathrm{a}$ & $\begin{array}{l}1867 \\
(92)\end{array}$ & $\begin{array}{l}1929 \\
(9.6)\end{array}$ & a & $\begin{array}{l}1920 \\
(92)\end{array}$ & $\begin{array}{c}3395 \\
(11.9)\end{array}$ & $\mathrm{a}$ & $\begin{array}{c}3351 \\
(57.8)\end{array}$ & & & & $\begin{array}{l}2085 \\
(8.3)\end{array}$ & a & $\begin{array}{c}2224 \\
(53.4)\end{array}$ & & & \\
\hline & $D(\mathrm{~ms})$ & $\begin{array}{c}36.2 \\
(19.9)\end{array}$ & a & $\begin{array}{c}34.1 \\
(193.5)\end{array}$ & $\begin{array}{c}33.8 \\
(19.8)\end{array}$ & a & $\begin{array}{c}34.5 \\
(77.2)\end{array}$ & $\begin{array}{l}114.7 \\
(26.7)\end{array}$ & a & $\begin{array}{l}115.4 \\
(88.5)\end{array}$ & $\begin{array}{l}135.9 \\
(29.2)\end{array}$ & a & $\begin{array}{c}120.5 \\
(110.3)\end{array}$ & $\begin{array}{c}33.5 \\
(15.7)\end{array}$ & a & $\begin{array}{c}32.6 \\
(84.9)\end{array}$ & $\begin{array}{c}90.4 \\
(15.9)\end{array}$ & $\mathrm{b}$ & $\begin{array}{c}92.1 \\
(35.5)\end{array}$ \\
\hline & Slope & $\begin{array}{c}43.6 \\
(29.4)\end{array}$ & a & $\begin{array}{c}45.1 \\
(193.7)\end{array}$ & $\begin{array}{c}41.4 \\
(28.7)\end{array}$ & a & $\begin{array}{c}40.7 \\
(179.1)\end{array}$ & & & & & & & & & & & & \\
\hline & $\operatorname{Amf}(\mathrm{Hz})$ & & & & & & & $\begin{array}{l}3206 \\
(7.9)\end{array}$ & a & $\begin{array}{c}3182 \\
(34.2)\end{array}$ & $\begin{array}{c}24.3 \\
(754.9)\end{array}$ & - & $\begin{array}{c}67 \\
(298)\end{array}$ & $\begin{array}{c}1462 \\
(11.8)\end{array}$ & a & $\begin{array}{c}1582 \\
(66.3)\end{array}$ & $\begin{array}{l}2915 \\
(10.6)\end{array}$ & a & $\begin{array}{c}3015 \\
(52.5)\end{array}$ \\
\hline \multirow[t]{4}{*}{ Part 2} & $D(\mathrm{~ms})$ & & & & 135.1 & a & 134.8 & & & & & & & 68.9 & - & 71.7 & & & \\
\hline & $\mathrm{CH} 2$ : break & & & & (21.8) & & $(92.7)$ & & & & & & & $(58.3)$ & & $(33.5)$ & & & \\
\hline & Ftop $(\mathrm{Hz})$ & & & & & & & $\begin{array}{l}3876 \\
(6.6)\end{array}$ & a & $\begin{array}{c}3848 \\
(31.2)\end{array}$ & $\begin{array}{c}2254 \\
(33.7)\end{array}$ & $\mathrm{a}$ & $\begin{array}{c}2963 \\
(114.2)\end{array}$ & $\begin{array}{c}3414 \\
(8)\end{array}$ & a & $\begin{array}{c}3653 \\
(53.4)\end{array}$ & $\begin{array}{l}3541 \\
(8.8)\end{array}$ & a & $\begin{array}{l}3663 \\
(47)\end{array}$ \\
\hline & $\operatorname{Amf}(\mathrm{Hz})$ & & & & & & & & & & & & & $\begin{array}{c}750 \\
(49.2)\end{array}$ & - & $\begin{array}{c}797 \\
(71.4)\end{array}$ & & & \\
\hline \multirow[t]{5}{*}{ Part 3} & $F$ start $(\mathrm{Hz})$ & & & & $\begin{array}{c}1569 \\
(28.6)\end{array}$ & $\mathrm{b}$ & $\begin{array}{c}1577 \\
(60.9)\end{array}$ & & & & $\begin{array}{c}2230 \\
(32.4)\end{array}$ & a & $\begin{array}{c}2896 \\
(110.1)\end{array}$ & $\begin{array}{c}1456 \\
(16.5)\end{array}$ & a & $\begin{array}{c}1482 \\
(49.1)\end{array}$ & & & \\
\hline & $F$ end $(\mathrm{Hz})$ & & & & $\begin{array}{c}611 \\
(28.3)\end{array}$ & - & $\begin{array}{c}609 \\
(30.7)\end{array}$ & & & & $\begin{array}{c}1950 \\
(40.8)\end{array}$ & a & $\begin{array}{c}1540 \\
(190.8)\end{array}$ & $\begin{array}{c}649 \\
(13.1)\end{array}$ & a & $\begin{array}{c}623 \\
(46.9)\end{array}$ & $\begin{array}{c}966 \\
(62.3)\end{array}$ & a & $\begin{array}{c}973 \\
(216.5)\end{array}$ \\
\hline & $D(\mathrm{~ms})$ & & & & $\begin{array}{c}53.4 \\
(65.4)\end{array}$ & a & $\begin{array}{c}55 \\
(293)\end{array}$ & & & & $\begin{array}{c}82.9 \\
(64.4)\end{array}$ & - & $\begin{array}{c}97.7 \\
(55.1)\end{array}$ & $\begin{array}{c}39.4 \\
(29.2)\end{array}$ & $\mathrm{a}$ & $\begin{array}{c}36.8 \\
(242.5)\end{array}$ & $\begin{array}{l}157.6 \\
(22.3)\end{array}$ & a & $\begin{array}{l}149.5 \\
(91.4)\end{array}$ \\
\hline & Slope & & & & $\begin{array}{c}22.9 \\
(38.6)\end{array}$ & a & $\begin{array}{c}22.8 \\
(184.3)\end{array}$ & & & & & & & & & & & & \\
\hline & $\operatorname{Amf}(\mathrm{Hz})$ & & & & & & & $\begin{array}{c}481 \\
(85.9)\end{array}$ & $\mathrm{c}$ & $\begin{array}{c}497 \\
(166.6)\end{array}$ & $\begin{array}{c}1183 \\
(68.1)\end{array}$ & - & $\begin{array}{c}1423 \\
(68.1)\end{array}$ & $\begin{array}{c}807 \\
(30.2)\end{array}$ & a & $\begin{array}{c}859 \\
(102.1)\end{array}$ & $\begin{array}{l}2575 \\
(22.8)\end{array}$ & a & $\begin{array}{r}2690 \\
(62.3)\end{array}$ \\
\hline Call & $D(\mathrm{~ms})$ & & & & & & & & & & & & & $\begin{array}{l}235.1 \\
(12.5)\end{array}$ & $\mathrm{b}$ & $\begin{array}{l}238.5 \\
(27.6)\end{array}$ & & & \\
\hline \multirow[t]{2}{*}{ Osc } & $\operatorname{Amf}(\mathrm{Hz})$ & & & & & & & & & & & & & & & & $\begin{array}{c}424 \\
(17.9)\end{array}$ & $\mathrm{b}$ & $\begin{array}{c}451 \\
(39.9)\end{array}$ \\
\hline & $D(\mathrm{~ms})$ & & & & & & & & & & & & & & & & $\begin{array}{c}27.7 \\
(17.3)\end{array}$ & - & $27.4(16.1)$ \\
\hline
\end{tabular}

- denotes not significant.

${ }^{\mathrm{a}} p<0.001$.

${ }^{\mathrm{b}} p<0.01$.

${ }^{\mathrm{c}} p<0.05$. 
${ }^{1}$ A. Lemasson, "What can forest guenons « tell » us about the origin of language?," in Primate Communication and Human Language: Vocalisations, Gestures, Imitation, and Deixis in Humans and Non-humans, edited by A. Vilain, J. L. Schwartz, C. Abry, and J. Vauclair (John Benjamins, Amsterdam, 2011), pp. 39-70.

${ }^{2}$ J. P. Gautier and A. Gautier-Hion, "Communication in old world monkeys," in How Animals Communicate, edited by T. E. Sebeok (Indiana University Press, Bloomington, 1977), pp. 890-964.

${ }^{3}$ A. M. Elowson and C. T. Snowdon, "Pygmy marmosets (Cebuella pymaea) modify vocal structure in response to changed social environment," Anim. Behav. 47, 1267-1277 (1994).

${ }^{4} \mathrm{H}$. Sugiura, "Vocal exchange of coo calls in Japanese macaques," in Primate Origins of Human Cognition and Behaviour, edited by T. Matsuzawa (Springer, Tokyo, 2001), pp. 135-154.

5 J. C. Mitani and K. L. Brandt, "Social factors influence the acoustic variability in the long-distance calls of male chimpanzees," Ethology 96, 233252 (1994).

${ }^{6}$ R. M. Seyfarth and D. L. Cheney, "Some general features of vocal development in nonhuman primates," in Social Influences on Vocal Development, edited by C. T. Snowdon and M. Hausberger (Cambridge University Press, Cambridge, 1997), pp. 249-273.

${ }^{7}$ M. J. Owren and R. H. Bernacki, "The acoustic features of vervet monkey alarm calls (Cercopithecus aethiops)," J. Acoust. Soc. Am. 5, 1927-1935 (1988).

${ }^{8}$ C. T. Snowdon, A. M. Elowson, and R. S. Roush, "Social influences on vocal development in new world primates," in Social Influences on Vocal Development, edited by C. T. Snowdon and M. Hausberger (University Press, Cambridge, 1997), pp. 234-248.

${ }^{9}$ A. Lemasson, A. Boutin, S. Boivin, C. Blois-Heulin, and M. Hausberger, "Horse (Equus caballus) whinnies, a source of social information," Anim. Cogn. 12, 693-704 (2009).

${ }^{10}$ I. Charrier, N. Mathevon, and P. Jouventin, "Vocal signature recognition of mothers by fur seal pups," Anim. Behav. 65, 543-550 (2003).

${ }^{11}$ M. B. Manser, R. M. Seyfarth, and D. L. Cheney, "Suricate alarm calls signal predator class and urgency," Trends Cogn. Sci. 6, 55-57 (2002).

${ }^{12} \mathrm{D}$. T. Blumstein and K. B. Armittage, "Alarm calling in yellow-bellied marmots: I. The meaning of situationally variable alarm calls," Anim. Behav. 53, 143-171 (1997).

${ }^{13}$ M. J. Owren and D. Rendall, "Sound on the rebound: Bringing form and function back to the forefront in understanding nonhuman primate vocal signaling," Evol. Anthropol., 10, 58-71 (2001).

${ }^{14}$ A. Lemasson, C. Blois-Heulin, R. Jubin, and M. Hausberger "Female social relationships in a captive group of Campbell's monkeys," Am. J. Primatol. 68, 1161-1170 (2006).

${ }^{15}$ A. Lemasson, E. Gandon, and M. Hausberger, "Attention to elders' voice in nonhuman primates," Biol. Lett. 6, 325-328 (2010).

${ }^{16} \mathrm{~K}$. Ouattara, A. Lemasson, and K. Zuberbühler, "Campbell's monkeys use affixation to alter call meaning," PloS ONE, 4 (11), e7808 (2009).

${ }^{17} \mathrm{~K}$. Ouattara, A. Lemasson, and K. Zuberbühler, "Generating meaning with finite means in Campbell's monkeys," Proc. Natl. Acad. Sci. U.S.A. 106(51), 22026-22031 (2009).

${ }^{18}$ T. T. Struhsaker, "Phylogenetic implications of some vocalizations of $\mathrm{Cer}$ copithecus monkeys," in Old World Monkeys: Evolution, Systematics and Behavior, edited by J. R. Napier and P. H. Napier (Academic Press, New York, 1970), pp. 365-444.

${ }^{19} \mathrm{P}$. Marler, "A comparison of vocalizations of red-tailed monkeys and blue monkeys (Cercopithecus ascanius and C. mitis) in Uganda," Z. Tierpsychol. 33, 223-247 (1973)

${ }^{20}$ J.-P. Gautier, "Comparative study of the systems of sound intercommunication in some African forest cercopithecins" (in French), Ph.D dissertation, Université de Rennes, France, 1975.

${ }^{21}$ A. Lemasson, J. P. Gautier, and M. Hausberger, "Vocal similarities and social bonds in Campbell's monkey." C.R. Biol. 326, 1185-1193 (2003).

${ }^{22}$ A. Lemasson and M. Hausberger, "Patterns of vocal sharing and social dynamics in a captive group of Campbell's monkeys," J. Comp. Psychol. 118, 347-359 (2004).

${ }^{23}$ A. Lemasson, K. Zuberbühler, and M. Hausberger, "Socially meaningful vocal plasticity in Campbell's monkeys," J. Comp. Psychol. 119, 220-229 (2005).
${ }^{24}$ K. Ouattara, K. Zuberbühler, K. E. N'goran, J. E. Gombert, and A. Lemasson, "The alarm call system of female Campbell's monkeys," Anim. Behav. 78, 35-44 (2009).

${ }^{25}$ J.-P. Gautier, "Qualities and drawbacks of radiotransmitted vocalizations of monkey through laryngophoned: New perspectives in analysis," Folia Primatol. 41, 218-230 (1983).

${ }^{26}$ A. Lemasson, J. P. Richard, and M. Hausberger, "A new methodological approach to context analysis of call production," Bioacoustics 14, 111125 (2004).

${ }^{27}$ A. Lemasson, "Vocal communication and social organisation in Campbell's monkeys (Cercopithecus c. campbelli)" (in French), Ph.D. dissertation, Université de Rennes, 2003.

${ }^{28}$ D. E. Gammon and M. C. Baker "Song repertoire evolution and acoustic divergence in a population of black-capped chickadees, Poecile atricapillus," Anim. Behav. 68, 903-913 (2004).

${ }^{29} \mathrm{P}$. Robisson, T. Aubin, and J. C. Brémond, "Individuality in the voice of emperor penguin A ptenodytes forsteri: Adaptation to a noisy environment," Ethology 94, 279-290 (1993).

${ }^{30}$ E. R. Patel and M. J. Owren, "Acoustics and behavioral contexts of 'gecker' vocalizations in young rhesus macaques (Macaca mullata)," J. Acoust. Soc. Am. 121(1), 575-585 (2007).

${ }^{31}$ C. T. Snowdon and M. Hausberger, Social Influences on Vocal Development (University Press, Cambridge, 1997).

${ }^{32} \mathrm{~K}$. Hammerschmidt and J. Fischer, "The vocal repertoire of Barbary macaques: A quantitative analysis of a graded signal system," Ethology 104, 203-216 (1998).

${ }^{33} \mathrm{C}$. H. Brown and P. M. Waser, "Environmental influences on the structure of primate vocalizations," in Primate Vocal Communication, edited by D. Todt, P. Goedeking, and D. Symmes (Springer-Verlag, New York, 1988), pp. 51-66.

${ }^{34}$ P. Marler, "Vocalizations of East African monkeys. I: Red colobus," Folia Primatol. 13, 81-91 (1970).

${ }^{35}$ H. Bouchet, A. S. Pellier, C. Blois-Heulin, and A. Lemasson, "Sex differences in the vocal repertoire of adult red-capped mangabeys (Cercocebus torquatus): A multi-level acoustic analysis,” Am. J. Primatol. 72, 360-375 (2010).

${ }^{36}$ S. Green, "The variation of vocal pattern with social situation in the Japanese monkey (Macaca fuscata): A field study," in Primate Behavior, edited by L. Rosenblum (Academic Press, New York, 1975), vol. 4, pp. 1-102.

${ }^{37}$ D. Rendall, R. M. Seyfarth, D. L. Cheney, and M. J. Owren, "The meaning and function of grunt variants in baboons," Anim. Behav. 57, 583-592 (1999).

${ }^{38} \mathrm{H}$. Koda, "Flexibility and context-sensitivity during the vocal exchange of coo calls in wild Japanese macaques (Macaca fuscata yakui)," Behaviour 141, 1279-1296 (2004)

${ }^{39}$ A. Searby and P. Jouventin, "Mother-young acoustic recognition in sheep: A frequency coding," Proc. R. Soc. London B 270, 1765-1771 (2003).

${ }^{40}$ J. C. Mitani, J. Gros-Louis, and J. M. Macedonia, " Selection for acoustic individuality within the vocal repertoire of wild chimpanzees," Int. J. Primatol. 17, 569-583 (1996).

${ }^{41}$ B. McCowan and S. L. Hooper, "Individual acoustic variation in Belding's ground squirrel alarm chirps in the High Sierra Nevada." J. Acoust. Soc. Am. 111, 1157-1160 (2002).

${ }^{42}$ D. Rendall, P. S. Rodman, and R. E. Edmond "Vocal recognition of individuals and kin in free-ranging rhesus monkeys," Anim. Behav. 51, 10071015 (1996).

${ }^{43}$ P. J. O. Miller, A. D. Shapiro, P. L. Tyack, and A. R. Solow, "Call-type matching in vocal exchanges of free-ranging resident killer whales, Orcinus orca," Anim. Behav. 67, 1099-1107 (2004).

${ }^{44} \mathrm{~S}$. Yin and B. McCowan, "Barking in domestic dogs: context specificity and individual identification," Anim. Behav. 68, 343-355 (2004).

${ }^{45}$ M. J. Owren, R. M. Seyfarth, and D. L. Cheney, "The acoustic features of vowel-like grunt calls in chacma baboons (Papio cynocephalus ursinus): Implications for production processes and functions," J. Acoust. Soc. Am. 101, 2951-2963 (1997)

${ }^{46}$ T. R. Riede, B. Mitchell, I. Tokuda, and M. J. Owren, "Characterizing noise in nonhuman vocalizations: Acoustic analysis and human perception of dog and coyote barks," J. Acoust. Soc. Am., 118, 514-522 (2005). 